\title{
Habitantes do Arroio: memória ambiental das águas urbanas ${ }^{1}$
}

\section{"Habitantes do Arroio": Environmental Memory of the Urban Waters}

\author{
Rafael Victorino DEVOS* \\ Ana Paula Marcante SOARES** \\ Ana Luiza Carvalho da ROCHA***
}

\begin{abstract}
RESUMO
Este trabalho apresenta os avanços teórico-metodológicos do projeto "Habitantes do Arroio". Investigam-se as situações de conflito e interdependência entre grupos sociais diversos, instituições e técnicos da área ambiental envolvidos cotidianamente com os usos das águas do Arroio Dilúvio, em Porto Alegre, RS, Brasil. A pesquisa se vale da produção e da exibição de documentários e narrativas visuais sobre as condições ambientais dos recursos hídricos, a diversidade sociocultural de representações simbólicas, ethos e visão de mundo das populações que habitam a bacia do Arroio Dilúvio. Das nascentes na encosta de morros, passando pela Avenida Ipiranga e chegando ao Lago Guaíba, encontramos muitas das contradições e desafios contemporâneos dos usos e cuidados com a água na cidade. A memória da transformação da paisagem com a canalização do Arroio Dilúvio revela muitas inter-relações entre as realidades socioambientais de bairros nobres, vilas e favelas, zonas comerciais e operárias, que podem ser evocadas em imagens de um ambiente urbano que se percebe pelo conflito, pelo contraste.
\end{abstract}

Palavras-chave: águas urbanas; risco; memória ambiental.

\begin{abstract}
This work discusses the theoretical and methodological advances of the project "Habitantes do Arroio". This research investigates conflict and interdependence situations between different social groups, institutions and technicians using the waters of Arroio Dilúvio in Porto Alegre, Brazil. The research uses documentary films about the environmental conditions of the basin, the socio-cultural diversity, ethos and world vision of its inhabitants. From the sources in the slope of the hills, passing by Ipiranga Avenue until the Guaíba Lake, we found many of the contradictions and contemporary challenges about the usage of and care for the water in the city. The memory of the transformation of the landscape of
\end{abstract}

\footnotetext{
${ }^{1}$ Trabalho apresentado em versão inicial durante a VIII Reunião de Antropologia do Mercosul, no GT Práticas e Saberes Territoriais - "Prácticas y Saberes Territoriales Conflictos y Dinámicas de Apropiación Cultural del Ambiente", Buenos Aires, 2009.

"Doutor em Antropologia Social pelo PPGAS - UFRGS. Pesquisador Associado ao BIEV - PPGAS - UFRGS e Professor do Departamento de Antropologia e PPGAS - UFSC. Email: rafaeldevos@yahoo.com

${ }^{* *}$ Mestre em Direito Ambiental - UFSC. Doutoranda PPGAS - UFRGS. Docente na ULBRA - RS. Email: apmarcante@hotmail.com

*** Doutora em Antropologia Social. Coordenadora do BIEV - PPGAS - UFRGS. Email: miriabilis@gmail.com
} 
Arroio Dilúvio shows the relations among the socio-environmental realities of high-class neighborhoods, slums and working class neighborhoods. The research shows the urban environment by evoking images of conflict and contrast.

Key-words: urban waters; risk; environmental memory.

\section{Introdução}

As pedagogias ambientais contemporâneas apostam claramente na relação indivíduo/natureza, na qual uma razão triunfante encobre os impasses da relação tensional entre indivíduo/sociedade/natureza, como já demonstraram inúmeros estudos sobre o Individualismo como ideologia moderna (DUMONT, 1983; DUARTE, 1986). O "nosso" problema não está na relação do homem com a natureza, mas de homens e mulheres diversos com ambientes diversos, ou melhor, entre homens e mulheres diversos em ambientes diversos. Esta concepção de ambiente pode ser pensada com o uso de alguns conceitos que norteiam a pesquisa do projeto "Habitantes do Arroio: estudo de conflitos de uso de águas urbanas, risco, saúde pública e comunidade étnicas em Porto Alegre-RS" (CNPq) ${ }^{2}$.

A pesquisa é voltada para a descoberta das situações de conflito e interdependência entre grupos sociais diversos, instituições e técnicos de diversas áreas, envolvidos cotidianamente com os usos das águas do Arroio Dilúvio, em Porto Alegre. O "Habitantes do Arroio" se vale da produção e da exibição de documentários, relatórios e narrativas visuais sobre as condições ambientais dos recursos hídricos em questão contrapostos à diversidade sociocultural de representações simbólicas, ethos e visão de mundo das populações que habitam a sub-bacia do Arroio Dilúvio, em Porto Alegre-RS.

O projeto, iniciado em janeiro de 2009, tem duração até setembro de 2010. Seus resultados e imagens produzidas podem ser conferidos no blog do projeto $-<\mathrm{http}$ ://habitantesdoarroio.blogspot.com> - que é já um primeiro esboço de uma cosmografia do Arroio Dilúvio, que propomos ${ }^{3}$ realizar por meio da investigação da memória ambiental. Este texto apresenta, particularmente, alguns arranjos diversos entre a paisagem alagadiça da bacia do Arroio Dilúvio e a paisagem urbana da cidade, expressos no cotidiano dos diferentes pontos da bacia observados durante a pesquisa de campo e nos relatos de diferentes personagens entrevistados, refletindo sobre as contribuições dos estudos sobre memória urbana para a investigação da complexidade socioambiental contemporânea.

\section{Ambiente e conflito}

Em meio ao debate público em torno da questão ambiental, a implementação de políticas públicas de preservação e conservação do meio ambiente, em âmbitos nacional e internacional, tem reservado atenção destacada aos recursos hídricos. Atualmente, enfrentam-se sérios riscos de escassez em que a demanda por água é maior que a oferta (numa escala global) e a crescente poluição deste recurso natural implica em graves riscos à saúde humana. Tais concepções de riscos (DOUGLAS, 1992), assim como as responsabilidades para com a qualidade das águas próprias para o consumo humano, situam os conflitos socioambientais em novos arranjos territoriais, como as bacias hidrográficas, pensadas não apenas como ecossistemas com uma dinâmica hídrica, mas, sobretudo, como territórios sobrepostos, em que se expressam diversidades socioculturais que atravessam limites políticos como o município e mesmo as fronteiras nacionais em alguns casos.

Entre o risco e a poluição das águas expressam-se diferentes éticas (OLIVEIRA; OLIVEIRA, 1996) de relação entre população/ambiente/população, ou seja, relações sociais mediadas pela dimensão ambiental em águas são um elemento importante. Conflito, neste caso, não significa

\footnotetext{
${ }^{2}$ O projeto é financiado pelo Conselho Nacional de Desenvolvimento Científico e Tecnológico (CNPq), por meio da Seleção Pública de Propostas para Apoio a Projetos de Pesquisa Relacionados à Água e Saúde Pública constante no Edital MCT/CT-Hidro/CT-Saúde/CNPq N. ${ }^{\circ}$ 45/2008. Sob coordenação de Ana Luiza Carvalho da Rocha, é executado pelo Banco de Imagens e Efeitos Visuais (PPGAS - UFRGS) e pela ONG Instituto Anthropos.

${ }^{3}$ A equipe do projeto é composta pelos antropólogos Ana Luiza Carvalho da Rocha, Rafael Devos, Viviane Vedana e Anelise Gutterres; pela Mestre em Direito Ambiental Ana Paula Marcante Soares; pelas estudantes de Ciências Sociais Luna Carvalho, Deborah Beck e Renata Tomaz do Amaral Ribeiro, com consultoria do Engenheiro Sanitarista Paulo Renato Paim, da Bióloga Ana Elisabeth Carara e da antropóloga Cornelia Eckert.
} 
confronto efetivo, os conflitos de uso expressam a dimensão conflitiva (SIMMEL, 2004; LITTLE, 2006) enquanto princípio da realidade socioambiental contemporânea, articulando microéticas locais, macroéticas planetárias de preservação ambiental e mesoéticas onde se explicita uma dimensão política voltada para a negociação de tais conflitos entre a diversidade social e cultural contemporânea. Como ensina a antropologia urbana - ou os estudos de sociedades complexas no Brasil (VELHO, 1999; OLIVEN, 1995) -, a questão ambiental é uma tendência geral de reorientação de práticas cotidianas e de ambientalização (LOPES, 2006) da vida pública que, no entanto, se expressa de maneira plural e diversificada nos diferentes ecossistemas e realidades sociais implicados.

Com relação aos usos da água, especialmente, estabeleceu-se um gerenciamento sistemático para os recursos hídricos nas esferas federal e estadual no Brasil, seguindo o modelo francês de gestão pública da água, em oposição à privatização do recurso. Enquanto que no contexto das atividades agroindustriais estabeleceu-se um debate institucionalizado e pautado pelo direito ambiental e a negociação econômica, no contexto urbano esta questão está referida na municipalização dos serviços de esgotamento sanitário. Não se trata apenas da eficiência das instituições responsáveis, mas também das condições sanitárias das populações urbanas, que revelam descontinuidades em que a cidadania se encontra tensionada pela desigualdade social e pela diversidade territorial dos grupos urbanos.

$\mathrm{Na}$ escala municipal, os arroios passaram a ter uma importância estratégica. O Arroio Dilúvio nasce na Lomba do Pinheiro, zona Leste de Porto Alegre, na Represa da Lomba do Sabão. Recebe vários afluentes, como os arroios dos Marianos, Salso, Moinho, São Vicente e Cascatinha e deságua no Lago Guaíba após atravessar uma das principais avenidas da cidade, a Avenida Ipiranga, que percorre os 12 quilômetros de extensão canalizada do arroio. A sub-bacia do Dilúvio tem cerca de 80 quilômetros quadrados, dos quais 19\% estão localizados no município de Viamão. Em seu leito original, o riacho passava sob a Ponte de Pedra, que existe ainda hoje, perto do atual Largo dos Açorianos, no centro da cidade. A canalização do arroio e a alteração de sua foz, na primeira metade do século XX, foi realizada com o objetivo de evitar o alagamento de diversas áreas da cidade, mas acabou também por urbanizar, valorizar e remodelar uma imensa região da cidade.

\section{Memória ambiental}

O Arroio Dilúvio, que por volta da década de 1950 apresentava águas límpidas, encontra-se poluído, recebendo cerca de 50 mil metros cúbicos de terra e lixo todos os anos. Recentes ações do Departamento de Esgotos Pluviais de Porto Alegre vêm demonstrando que o Arroio Dilúvio ainda é bastante utilizado como esgoto cloacal, como escoamento de inúmeras áreas residenciais e comerciais da cidade. Os novos projetos de recuperação de suas águas dependem da contribuição, por parte dos proprietários de residências e edificações, na correta ligação do esgotos pluviais ou domésticos às redes que correm em separado ao longo do leito do Dilúvio. Esta adesão não ocorre, no entanto, pela simples constatação da crise ambiental, da poluição etc.

Pensando os serviços de saneamento, a produção de imagens documentais e a pesquisa científica como agentes de mediação entre microéticas locais de uso das águas e do solo e macroéticas planetárias (OLIVEIRA; OLIVEIRA, 1996) de promoção da proteção ambiental das áreas naturais, percebemos a importância da memória no processo de compreensão da inserção dos territórios urbanos na bacia hidrográfica. Acompanhando o trabalho de técnicos da companhia de saneamento municipal (DMAE), ao verificarem a correta ligação dos esgotos domésticos na rede pública, percebemos o grande desconhecimento e desinteresse por parte da população que reside em situação "regular" da destinação de seus esgotos e da origem da água que abastece sua residência ou dos seus espaços de circulação (áreas comerciais).

De fato, os recentes projetos de despoluição das águas que banham a cidade encontram a descrença de grande parte da população: para muitos, a poluição das águas ainda parece um preço irreversível a pagar pela constituição de uma sociedade urbano-industrial. E, no entanto, são justamente as lembranças de usos "populares" das águas na cidade que são evocadas em projetos atuais de recuperação da qualidade da bacia. Ainda é possível encontrar moradores que lembram com prazer de quando se banhavam nas águas do Guaíba e do Dilúvio, quando navegavam por arroios, quando bebiam a água diretamente do rio, quando pescavam, em que o tempo antigo remete a menos de 30, 40 anos. Aliás, em alguns pontos da bacia do Dilúvio, tais práticas ainda se fazem presentes, ainda que sejam consideradas contemporaneamente como exposição 
a situações de risco, como a contaminação por doenças, o afogamento de banhistas, sem contar as efetivas tragédias com as cheias.

A possibilidade de reinserção dos arroios na paisagem urbana é, portanto, uma possibilidade de reflexão sobre as dinâmicas da vida urbana e a dinâmica das águas. Durante a pesquisa, percebemos que as imagens produzidas pelo projeto, os relatos de moradores sobre os antigos caminhos dos arroios e as imagens antigas reunidas em acervos da cidade provocaram, em nossos interlocutores, uma revisão desse processo de urbanização através da compreensão das particularidades do ambiente urbano como apropriação da diversidade ambiental da região. Sobretudo, a constatação de que o Dilúvio não é um único arroio próprio do "ambiente original" da cidade - como o definem determinados discursos ambientalistas -, mas uma unidade construída ao longo do processo de saneamento e urbanização da cidade, provoca a imaginação a fazer o caminho inverso e repensar a diversidade de lugares, riachos e seus usos nos projetos futuros para a cidade.

A investigação da memória ambiental urbana é uma forma de compreender as transformações na paisagem urbana e na diversidade de itinerários de sua população, refletindo sobre os arranjos entre cidade e natureza, rompendo com um discurso homogêneo da degradação ambiental enquanto consequência geral da urbanização, cuja resposta estaria numa solução tecnológica.

A pesquisa sobre memória no meio urbano não é um mero registro do passado, mas sim uma reflexão sobre a duração, como propõem Eckert e Rocha (2005). As entrevistas realizadas com técnicos, moradores antigos, crianças e adolescentes, pedestres e motoristas tiveram o objetivo de descobrir as conexões diferenciadas que as pessoas estabelecem entre "tempos" diversos da trajetória ambiental da região, ou seja, interessa descobrir em que momentos e de que formas as suas narrativas percebem rupturas, o fim ou o começo de novos processos, ou o retorno e a repetição de antigas práticas, na relação da cidade com as águas e dos seus habitantes entre si a partir das águas. Da mesma maneira, investigamos nos acervos de imagens (fotografias, representações cartográficas) e de textos da cidade (cronistas) de que forma o Arroio Dilúvio aparecia como elemento de continuidade ou ruptura do urbano com o "natural" e vice-versa. Finalmente, na observação do cotidiano, das práticas diversas de moradores ou nas atividades dos técnicos da companhia de saneamento ou de operários das obras públicas, as conexões entre diferentes dinâmicas também podiam ser observadas nos deslocamentos e intervenções na paisagem urbana.

Sr. José, policial aposentado, morador da Travessa Pesqueiro, revela as imagens de sua infância, que ressoam nos nomes dos lugares narrados, que se aproximam das práticas e trajetos que condensam:

\begin{abstract}
Na época a gente não tinha conhecimento de obra grande assim. Só aquelas coisas que eles faziam para destrancar os valos aí. Na época eu tinha uns 9, 10 anos. Eu levantava e ia direto para a rua brincar de mãe d'água e soldado e ladrão. Ia lá para o riacho jogar futebol, pescar, e os canoeiros passavam ali e atiravam frutas para nós, era uma vida boa. E tinha mato ali onde nós fazíamos o nosso forte de brincadeira. Tinha a rixa entre o pessoal aqui da Cidade Baixa, da Joaquim Nabuco, a gente não era muito chegado neles e nem eles em nós, o pessoal da Ilhota também, e o pessoal do Areal era o meu pessoal aqui, né? A nossa turminha aqui da Pesqueiro era uma que a gente tinha um quartel, e o pai de um de nós era aposentado da brigada, é até hoje, eu também sou brigadiano, e ele trazia um capacete... que nem de bombeiro, e a gurizada usava no quartel pra combater os outros, era pedra pra cá e pedra prá lá. Eles fizeram uma tubulação onde nós brincávamos, do outro lado. Então nós brincávamos ali dentro. $\mathrm{E}$ apavoravam a gente $-\mathrm{A}$ hora que eles soltarem a água lá em cima vai morrer tudo afogado aí! Eu nunca mais entrei ali.
\end{abstract}

Um morador ainda mais antigo do Areal da Baronesa, Mestre Borel, tamboreiro de cultos afro-brasileiros (batuque), narra aos seus 84 anos as configurações destes territórios, enquanto uma espécie de ilhas ao mesmo tempo separadas pelas águas e ligadas por uma mesma característica de planície alagadiça.

Deixa eu contar uma história. Porto Alegre, centro. Quando estavam ainda fazendo o viaduto da Av. Borges, que estavam cavando lá. Naquela parte que já pegava da Borges para lá já era Cidade Baixa, na parte praia. Então João Alfredo, José do Patrocínio, a antiga Rua da Margem. [...] pela João Alfredo vinha até a rua da República. A rua da República tinha um pontilhão de madeira que passava para o pão dos pobres, era um arroio. Ela vinha até a praça Garibaldi, que o bonde dava a volta. [...] ali tinha um outro pontilhão. Está vendo que está isolando a Ilhota, a Ilhota está ficando ilhada. Seguindo ali tinha 
a Barão do Gravataí, ela descia até a [...] Cidade Baixa, o Pão dos Pobres... Então ele vinha fechando, ali quando chegava na André Belo tinha outro pontilhão, que não passava. Aí vinha até a 17 de junho, que chamava Rua dos Cachorros, tinha outro pontilhão lá embaixo, não passava. De modos que o Areal da Baronesa era um tipo de um arquipélago. E aqui era um riacho que era esse tal de arroio de Dilúvio... Ali onde é o Ernesto Dorneles, onde é o hospital, tudo era forno do lixo. Lixão. Não passava nada ali... morou ali aqueles que tinham carnaval $[. .$.$] e nós moramos ali também... A única rua$ que tinha ali que passava era a travessa São João.. aquilo ali era banhado, tinha chácara de português. Para ir para o Partenon se ia direto pela João Pessoa, aquilo ali também era um riacho que ligava lá embaixo na Ilhota... Moramos todo mundo ali... é um círculo, sabe? A gente da Ilhota, do Areal, esse núcleo de negros, sabe? Essa senzala que eu quero dizer abrangia tudo isso, pegava a Ilhota todinha, pegava o Areal da Baronesa todinho, até a Av. Borges, porque ali era zona de meretrício, ali era riacho também, não passava nada ${ }^{4}$.

Lugar da terra, da água e do mato, o arroio e suas margens se contrapunham à cidade das grandes avenidas, possuíam um curso sinuoso e labiríntico. Ao ser retificado com as reformas, também perdeu essa ocupação negra, com os processos de remoção de tais populações para regiões distantes na periferia da cidade e a valorização no mercado imobiliário da Cidade Baixa. No entanto, é ainda forte o axé de suas "esquinas sagradas" (SILVA, 1996) que guardam sua força da junção da encruzilhada com as águas subterrâneas da Mãe Oxum, o que pode ser percebido nas práticas rituais de casas de umbanda e batuque, próximas ou distantes do bairro, que marcam diferentes pontos sagrados nos seus percursos religiosos, nas festas anuais, nas oferendas, e manifestações contemporâneas pela liberdade de culto.

A pesquisa permitiu a descoberta da diversidade de redes sociais, de cotidianos diferenciados e projetos contemporâneos, escorados em uma memória que se enraíza neste elemento fundamental da cidade de Porto Alegre, as águas urbanas. A memória ambiental possui um papel importante na redescoberta das características ambientais dos territórios estudados, ou seja, áreas úmidas, sua biodiversidade e dinâmica hídrica, assim como suas implicações nas concepções de natureza e cultura. Tal memória se expressa nas narrativas orais de moradores de diferentes territórios interligados por arroios e afluentes, assim como por sistemas de esgoto e drenagem urbana. Os itinerários de tais populações revelam as transformações na paisagem de sub-bacias hidrográficas que contribuem para grandes corpos hídricos como o Lago Guaíba.

Marcadamente, suas lembranças de práticas cotidianas de uso das águas (lazer, abastecimento, higiene pessoal e doméstica, práticas religiosas) e sua reflexão sobre as mudanças nos estilos de vida e na paisagem urbana revelam complexos territórios urbanos surgidos sobre as águas. As lembranças do antigo curso do arroio não canalizado o situam como parte da territorialidade de inúmeros grupos urbanos: "batuqueiros" praticantes de religiões afro-brasileiras e descendentes de ex-escravos, moradores dos antigos "arrabaldes" convertidos em bairros da cidade, migrantes da zona rural que situam a bacia do Dilúvio como local de enraizamento.

Considerada a maior obra de engenharia da cidade, a extensão de $12 \mathrm{~km}$ canalizada do arroio tem grande importância na drenagem do solo urbano, na prevenção de enchentes e, contemporaneamente, tem papel importante na separação dos esgotos domésticos dos esgotos pluviais. No entanto, as políticas ambientais contemporâneas, voltadas para a recuperação da qualidade de suas águas através da correta ligação dos esgotos domésticos nas redes de coleta, e o reforço de sua função de drenagem de água da chuva, corredor ecológico, encontram resistência não só na dimensão doméstica do saneamento, mas também na própria relação do arroio com as vias urbanas. O pouco espaço na margem e os taludes com grama e árvores não são um convite suficiente para usos diversos que propiciem o seu reconhecimento como espaço "natural" em meio ao urbano, pela forte circulação de veículos ao longo da via. Como reconverter em arroio o canal que se mostra como "Monumento ao automóvel" (SCLIAR, 1976), na difícil travessia do asfalto das autopistas para chegar ao pouco espaço de uso público em suas margens?

Uma pista pode ser encontrada na memória dessa canalização, pensando seus impactos diversos nos arranjos entre cidade e natureza. Algumas representações em mapas e desenhos da morfologia de morros e áreas baixas da bacia

\footnotetext{
${ }^{4}$ A narrativa de Mestre Borel, que faz parte do material do projeto, compõe também o documentário "Mestre Borel e a ancestralidade negra em Porto Alegre", 2010, direção de Anelise Gutterres, realizado por integrantes da equipe do projeto Habitantes do Arroio.
} 
apresentam tal ambiente "original" retirando a urbanização como se a mesma fosse uma camada a mais acrescentada ao meio, o que de certa forma participa de um sentimento de "volta", "recuperação" do arroio a uma forma original. Ora, o que as narrativas mostram é que a obra é parte desse ambiente. Sr. Leopoldino Borges, engenheiro que estava à frente da finalização da obra de canalização nos anos 1960, narra como "foi feito" o Arroio Dilúvio:

Imagine, tire fora a Ipiranga. O que sobra ali? A obra do Arroio Dilúvio ela modificou Porto Alegre. Ela deu um outro aspecto a Porto Alegre. O Dilúvio foi feito pelo DNOS, Departamento Nacional de Obras de Saneamento. O Dilúvio era um arroio que transbordava, causava inundação nos bairros de Porto Alegre... 1967, houve uma enchente grande. A prefeitura já tinha começado um princípio de escavação no leito do Dilúvio, na Rua da Margem até a Azenha. Daí fizeram a escavação até a Rua Santana e não fizeram nada, não tiveram recursos... Então eu passei a noite lá, com a draga e tudo mais, e aí nós rompemos, aí toda a inundação que tinha na zona do hospital baixou tudo em questão de duas horas desceu tudo. Foi a grande demonstração do valor do Arroio Dilúvio. Daí continuamos, fomos embora, até o Beco do Salso.
O que fica claro nas entrevistas com alguns engenheiros e técnicos de saneamento, e mesmo na observação do ritmo cotidiano do fluxo de pessoas à margem do arroio na Avenida Ipiranga, é que sua canalização se confunde com a própria construção da autopista. O saneamento, como já foi recorrentemente debatido, constituiu-se em higienização e distinção social de territórios (CORBIN, 1986). O arroio se torna para além de fronteira, de separação e ligação entre territórios vizinhos, um local de passagem, inserindo-se numa homogeneização do espaço urbano. Ainda que inúmeros arroios e pequenos contribuintes (os arroios sem nome, as sangas, os riachos, os valos) de sua bacia ainda percorram o interior de diferentes territórios, o Dilúvio parece à parte dessa bacia e seus meandros, apresentando-se como uma unidade, uma linha que atravessa a cidade, mas que está "fora", no limite entre um bairro e outro, entre um lugar e outro, um obstáculo a ser cruzado nos caminhos cotidianos de pedestres, passageiros e motoristas. Permanecer na margem do arroio, nas áreas de maior movimento é prática recorrente apenas dos trabalhadores das sinaleiras, pedintes e nômades urbanos.

Acompanhando tais itinerários, percebemos que o caminho do arroio cruzando tais territórios se confunde com o sistema viário - ruas, acessos, becos e mesmo a grande Avenida Ipiranga são itinerários que consolidaram, no pro-

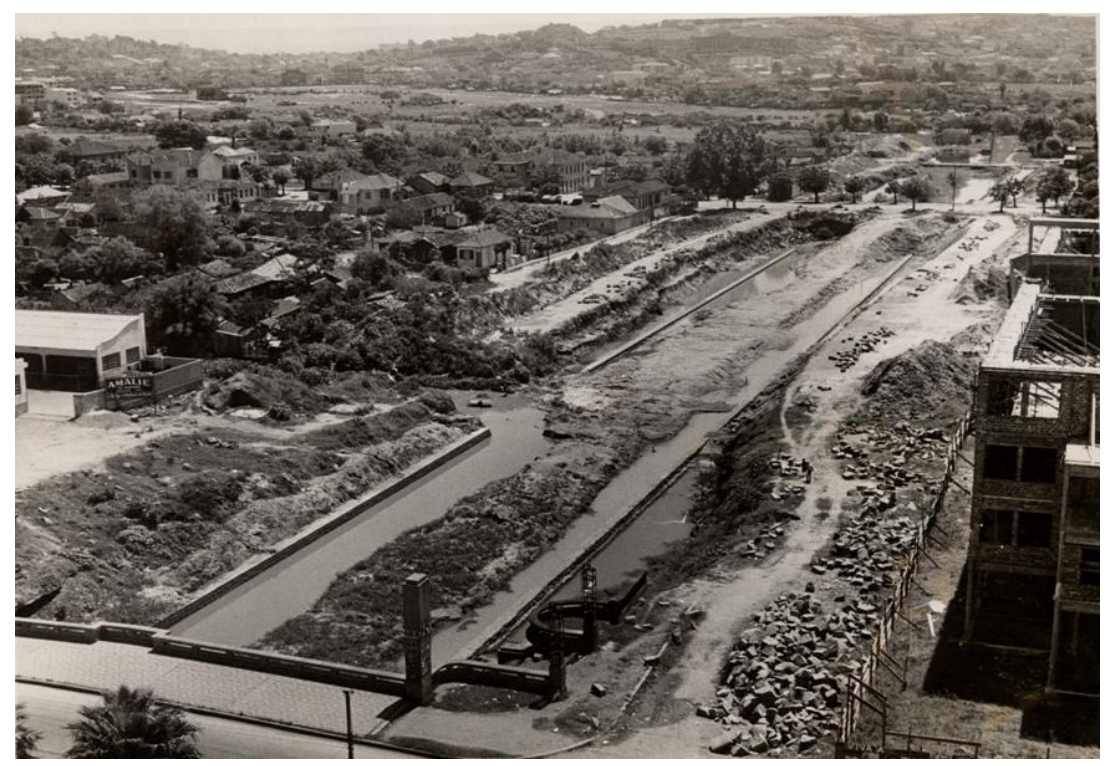

FIGURA 1 - CANALIZAÇÃO DO ARROIO DILÚVIO ENTRE PONTE DA AV. JOÃO PESSOA E RUA SANTANA - 1951. FONTE: MUSEU DE PORTO ALEGRE JOAQUIM FELIZARDO. AUTOR: DESCONHECIDO. 


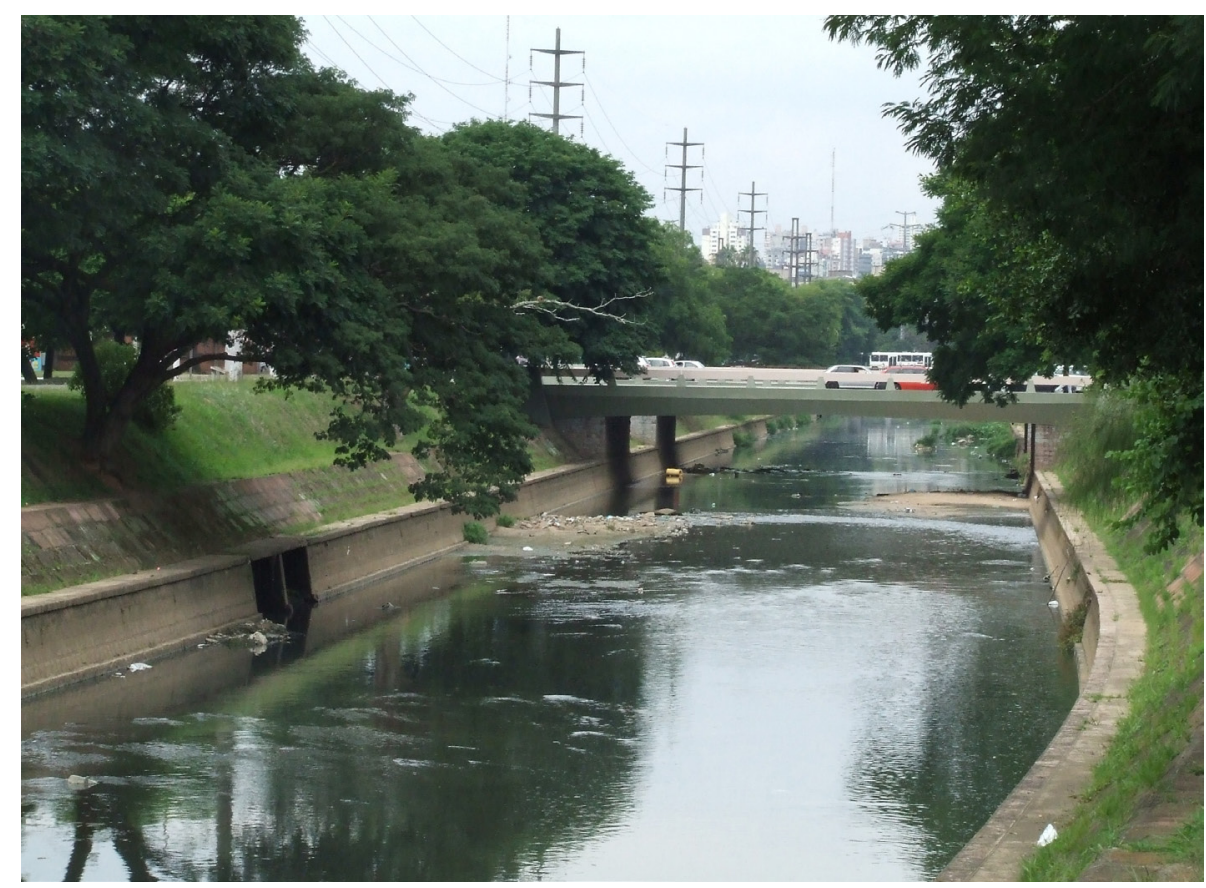

FIGURA 2 - ARROIO DILÚVIO. PONTE AVENIDA ÉRICO VERÍSSIMO E AV. IPIRANGA - 2009. AUTOR: LUNA CARVALHO (BIEV-PPGAS-UFRGS).

cesso de urbanização da cidade, a associação dos arroios a esta propriedade de delimitação de fronteiras. No caso das ocupações irregulares, o processo de ocupação da margem implica no aterramento de parte da margem, redesenhando a relação do solo com a água, cujo contraponto é a luta contra a ação devoradora da água na constante reconstrução de pontes de acesso, no reforço da "barranca" do leito do arroio com sacos de areia, no cultivo de espécies vegetais que "segurem" o solo. As narrativas dos engenheiros envolvidos na grande canalização do arroio nos anos 1950 e as imagens de acervo que encontramos seguem, numa escala muito maior, a mesma perspectiva de "domar" o arroio, conquistar e controlar sua ação sobre o solo e desenhar os itinerários da cidade.

Recebemos, ao longo da pesquisa, projetos contemporâneos, de usos para o lazer, para a circulação de pessoas, bicicletas. Mas também não foram poucas as propostas que percebemos de eliminação por completa do arroio da paisagem urbana, via canalização subterrânea, para criação de nova via pública para automóveis, trens etc. As propostas contemporâneas de retomada da presença dos arroios e de suas margens "naturais" na paisagem urbana, para partici- parem no controle das cheias com a drenagem da água da chuva, encontram como obstáculo este longo processo de associação dos arroios às ruas e avenidas da cidade enquanto espaços que marcam a passagem dos microcosmos da casa e da vizinhança para o universo da cidade. Da mesma maneira, embora valorizem as qualidades das águas e áreas verdes, as ocupações das margens dos arroios também dão continuidade a aterramentos e à utilização do arroio como esgoto nas subdivisões das propriedades, trocas, vendas e acordos que medeiam a ocupação do solo urbano. E são, no entanto, alguns destes moradores que encontramos em práticas de lazer, assim como em ações de limpeza, de retirada de lixo das águas do arroio, de reconstrução das pontes, de retomada de um cotidiano em contato com as águas.

Essa longa relação com estes territórios revela a importância dos itinerários urbanos (ECKERT; ROCHA, 2005; DEVOS, 2007), a repetição dos gestos de fundação e refundação de lugares e trajetos significados a partir dos saberes e práticas culturais, em especial, a refundação da casa como espaço de moradia em um novo terreno a ser ocupado. Tais itinerários revelam uma longa construção dos aspectos simbólicos liminares de tais paisagens associadas 
ao perigo, à miséria, à doença em determinadas narrativas, mas também remetendo à infância, à religiosidade e à evasão.

Quando se imagina que a cidade está já "de costas" paras as águas, como reivindicam protestos ambientalistas, os usos cotidianos das águas como espaço de lazer e circulação por parte das camadas populares retomam uma sociabilidade associada à velha cidade das lavadeiras, dos barqueiros, cuja figura retorna na memória e nos gestos cotidianos de relação com um arroio agora considerado poluído, degradado, morto. Por outro lado, as ações de recuperação das áreas de nascentes do Arroio Dilúvio mal disfarçam a proliferação de condomínios residenciais de alto padrão, ecologicamente corretos, que passam a valorizar áreas verdes próximas aos arroios, aproveitando a instalação de redes de infraestrutura viária e sanitária na região. Portanto, o chamado "divórcio" da cidade com as águas não se aplica a todas as pessoas, como processo homogêneo.

Como alguns estudos revelam (ROCHA, 1994; MONTEIRO, 2001), Porto Alegre viveu no século XX um processo de urbanização em que ocorreu uma ruptura com uma paisagem urbana rural/rústica marcada por suas características ambientais (orla, porto, matas etc.) em direção a uma vida urbana identificada com as reformas, as grandes avenidas, as grandes construções, em que as características ambientais dos territórios, sobretudo as áreas úmidas, constituíram-se em obstáculo ao avanço do asfalto e de um projeto de civilização. Como um contraponto a este processo, foram justamente tais áreas baixas, alagadiças, que serviram de território de enraizamento dos projetos de ex-escravos, de migrantes da área rural, de trabalhadores urbanos que combinaram os deslocamentos na cidade com a autoconstrução da moradia e o uso do pátio como espaço doméstico importante. No século XXI, as novas reformas urbanas voltam-se para a revisão desse processo, debatendo as possibilidades de despoluição das águas, de usos públicos das áreas naturais (sobretudo as áreas úmidas), de institucionalização de responsabilidades e direitos ambientais, de transformação de costumes ligados à higiene e à saúde pública.

A antropologia brasileira, tanto por parte dos estudos que se intitulam enquanto "Antropologia Urbana", de pesquisa sobre o fenômeno urbano, quanto seus desdobramentos em termos de pesquisas $n a$ cidade (VELHO, 1981), têm colocado o problema da diferenciação interna das sociedades contemporâneas, que não se apresenta como dado, mas como uma dinâmica relacionada à diversidade de papéis sociais desempenhados na vida cotidiana, aos diferentes universos simbólicos constituídos a partir das diferentes redes de significados compartilhadas pelos indivíduos em suas ações cotidianas, pelas quais a realidade é negociada (VELHO, 1981; 1999).

Portanto, nessa perspectiva, importa menos a paisagem física do local onde as pessoas vivem e muito mais como elas vivem, articulando suas práticas no seu local de moradia à região em torno. A questão dos conflitos entre os diferentes grupos urbanos quanto à apropriação de determinados "bens difusos" como os cursos d'água - ou ambientes como banhados e margens de rios e arroios no meio urbano - se apresenta como um tema fascinante, na medida em que tais espaços possam ser pensados como "territorialidades flexíveis", conforme o conceito proposto pelo antropólogo Antônio Arantes (2000), como áreas densas da paisagem urbana onde identidades são contrastadas nas diferentes práticas sociais, onde sentimentos de pertencimento são afirmados em nome de identidades locais, em nome da nação ou em nome de filiações a correntes cosmopolitas como os movimentos ecológicos contemporâneos.

Os tais usos do arroio como lazer e fruição estética existem, portanto, na bacia do Dilúvio, mas os mesmos estão associados às condições de miséria e pobreza dos centros urbanos. Justamente as áreas consideradas por muitas pessoas como as mais "limpas" do arroio, nas nascentes, são áreas ocupadas de forma diferencial pelas favelas, ou vilas, da cidade. $\mathrm{O}$ que se torna necessário é o reconhecimento de que a recuperação das qualidades ambientais e hídricas do arroio passa pela dotação de condições sanitárias e de habitação para populações que se encontravam, até então, nos locais menos privilegiados da territorialidade urbana e que convivem de forma muito mais próxima com a face dadivosa do riacho tranquilo e com a face terrível do arroio que traz a fúria das águas, retomando lembranças de outras cheias e de outros tempos de enraizamento em tais regiões.

D. Maria, empregada doméstica aposentada, conta-nos sua relação ambígua com as águas do arroio:

Tavam para tirar a gente daí que eu até tenho o papel aí né? Tavam para tirar a gente até o dia 19 , dia 19 já passou, já estamos no fim do ano e até agora... toda reunião que tem eu vou lá. Aqui é a divisa de Viamão com Porto Alegre, Porto Alegre é para cá e Viamão é para lá. $\mathrm{O}$ arroio é o ditado que quando a gente entra a gente não sabe a situação do arroio, né? A gente como vê o arroio sempre correndo, não vê ele cheio, né? Aí 
quando a pessoa vê cheio é que a pessoa fica assustada, né? Ela vem até a rua, depois desce até o porão, achei que a casa ia junto. Quando eu comprei essa casa tava barato. Se o terreno fosse meu eu até ia fazer coisa melhor aqui. Mas como não é... Eu gosto dessa zona, mas só que as águas quando invadem... era bombeiro aqui, a polícia para tirar pessoas das águas. Essa velhinha que morreu está fazendo uns três anos que ela é morta já.

Neste ponto revela-se claramente que a memória não é a reprodução do passado, mas a sua elaboração criativa a partir de razões do presente. Entendida como duração, a memória é coletiva, nos termos de Halbwachs (1990), pois não se encontra na consciência de um indivíduo, mas sim nas representações de uma coletividade, nos símbolos, nos lugares, nas práticas e saberes em que esta se reconhece. É duração, nos termos de Eckert e Rocha (2005), pois é uma concepção de muitos "começos" de muitos desvios, de retornos em trajetórias no tempo, cujo ritmo é ditado pelo esforço de continuar. Como mostra Bachelard (1988), a continuidade (da cultura, do ser, do ambiente, poderíamos dizer) não é um dado imediato, é uma construção humana. E mesmo as possibilidades de mudança e de transformação são expressas nas imagens do tempo, nas suas formas: ciclos, retornos, mortes, recomeços, progressos - são todas modalidades de interpretação da passagem do tempo, que embora se expressem em narrativas individuais, são compartilhadas na dinâmica do imaginário, conforme Durand (2001).

\section{Paisagens urbanas}

Conforme a distinção filosófica entre as ideias de espaço e lugar (CAUQUELIN, 2002; CERTEAU, 1994), sendo o espaço abstrato, valorativo, mensurável, e sendo o lugar uma composição complexa mesclando tempo, meio e espaço em um enraizamento de memórias e singularidades, é a relação entre ambiente e lugar que pode ser reveladora para a pesquisa. É Marcel Mauss (2003) um dos autores na Antropologia que abre caminho para essa perspectiva, na medida em que estende a compreensão das categorias de espaço e tempo como representações coletivas enquanto investidas de afetividade, constituídas a partir de redes de relações sociais e reciprocidades, que acrescentam significados à divisão social do espaço, inserindo-o na dimensão vivida e, portanto, atualizada nas relações sociais.
A partir da noção de duração colocada por Mauss (2003), de tempos sociais compartilhados e inscritos nos espaços da vida cotidiana, desenvolve-se a perspectiva de investigação do espaço a partir da investigação dos tempos sobrepostos nos territórios onde a vida urbana, em especial, oferece uma grande variedade de durações. Enquanto ambiente, a cidade pode ser investigada pela variedade de relações sociais que se inscrevem nos seus espaços, e que os configuram.

É possível estender, sob o ponto de vista de um paradigma estético, inspirado na sociologia de Georg Simmel (1996; 2004), a interpretação dessas representações das formas da vida social a uma interpretação da dimensão vivida do cotidiano da cidade, como o fazem as antropólogas Cornelia Eckert e Ana Luiza Carvalho da Rocha (2005). Pensando a cidade como obra coletiva e os ambientes ditos naturais como espaços públicos, percebe-se a alusão dos arroios com as ruas, sendo marcados pelas diferentes formas de interação social.

Ensaia-se, portanto, uma aproximação com a abordagem fenomenológica do espaço proposta por A. Molles e E. Rohmer (1982), investigando o espaço da cidade como espaço vivido, seguindo os estudos de Gilbert Durand (2001) sobre o "espaço fantástico" da memória e Gaston Bachelard (2000) sobre a "poética do espaço", em que os lugares (e suas características ambientais) se conformam como modalidades de experiência espacial que não se apresentam de imediato pela constituição do espaço físico, mas pela forma como esse é praticado, significado e imaginado. Labirintos, microcosmos, ilhas, passagens, corredores, as experiências fenomenológicas do espaço são expressas nas narrativas orais dos sujeitos a serem entrevistados tanto quanto na própria situação etnográfica a ser proposta.

Conforme Michel de Certeau (1994), o lugar é inscrito por práticas cotidianas que atualizam seus significados dinamicamente, pois depende das táticas e ações cotidianas dos indivíduos para se perpetuarem enquanto lugar do próprio, da experiência singular. O lugar não existe apenas como uma representação que depende daquele que observa para ser percebida. A estética do lugar, ou o seu genius loci (MAFFESOLI, 1996, p. 272), o espírito do lugar, que constitui o espaço da vida social a partir de um compartilhar de emoções, de cheiros, de cores, de trajetos, de sons, de gestos e posturas, de referências em comum, está apoiada em uma ética, um comportamento cujos significados sociais se inscrevem nas ações dos sujeitos na forma de um ethos. 
O conceito de paisagem aproxima-se dessa concepção. Apesar de o termo originar-se no campo da representação pictórica renascentista do espaço, que objetiva determinado espaço a partir do olhar distanciado e em profundidade, enquanto obra da imaginação humana o conceito agrega também uma dimensão fabulatória que insere o tempo social dentro do espaço enquanto representação social. Conforme Simmel (1996), a paisagem é a decomposição e o recorte de elementos retirados da continuidade infinita da natureza, realizando a vontade humana em determinadas formas que se perpetuam no tempo. Segundo o autor, em um exemplo clássico, uma ponte é a realização da vontade de união de duas margens, a ponto de se fundir à própria paisagem, assim como a estrada é a concretização de um caminho repetido inúmeras vezes.

Na medida em que o arranjo dos elementos no quadro evoca significados acumulados no tempo que configuram uma determinada forma de ver elementos como edificações, vegetação, terra, água, num todo coerente (CAUQUELIN, 2002), a paisagem tem uma relação fundamental com a formação do que Halbwachs (1990) chama dos quadros sociais da memória, pois evoca determinados tempos sociais enquadrados no recorte espacial. Os quadros sociais da memória, a partir do ato de lembrar, rompem com a oposição entre a matéria e o espírito, sendo uma obra coletiva em que os grupos aos quais os indivíduos pertencem exercerão papel definitivo. Da mesma forma, podem-se perceber como lugares, objetos, ruas, árvores, dizendo respeito a uma ordem de ideias, interesses e preocupações que uma coletividade compartilha, porque contados e vividos no interior dos grupos como forma de permanecerem no tempo. A paisagem está expressa não só na pintura ou na fotografia, mas nos relatos orais e narrativas míticas que representam os cenários das ações narradas - na literatura igualmente se realiza esse arranjo de coisas e tempos no espaço.

Dessa forma, é refletindo a partir dos itinerários urbanos expressos nas trajetórias sociais dos indivíduos que a paisagem se configura na compreensão da passagem do tempo. Embora se trate de uma mesma bacia hidrográfica, a sub-bacia do Arroio Dilúvio, suas águas marcam a divisão deste espaço em regiões que são valorizadas diferencialmente, sendo, portanto, suas águas aludidas também não apenas a um único ambiente, mas a diversos riozinhos, riachos, valos e outros corpos hídricos que separam territórios e marcam lugares. É possível, assim, chegarmos a uma concepção do ambiente, relacionando a paisagem natural e a paisagem urbana a partir da experiência dos narradores/ interlocutores da pesquisa. Seguindo o mesmo percurso, chegaremos também a novas concepções de cidade, em que sua separação do mundo natural não seja nem constante nem absoluta, expressa nas práticas cotidianas e na memória socialmente elaborada. Para acessar tais dinâmicas da paisagem, o projeto se valeu da produção e do colecionamento de diferentes imagens que apresentam diferentes arranjos possíveis dessa diversidade.

\section{Uma cosmografia a partir da imagem}

Para narrar essa dinâmica, este projeto de pesquisa segue o desafio metodológico proposto por Paul Little (2006) de elaboração de uma cosmografia das territorialidades sobrepostas de grupos sociais, remetidas a determinado ambiente. Nesse sentido, elege-se o arroio, sua bacia ou sub-bacia hidrográfica em área urbana como universo a ser estudado. A pesquisa etnográfica atua, portanto, entre redes sociais distintas, que envolvem moradores residentes de tais territórios, mas também técnicos e agentes do poder público atuantes em políticas e serviços na área ambiental, assim como abrange outros habitantes da cidade referidos a tais territórios, como ex-moradores, adeptos dos movimentos ambientalistas, agentes dos setores comerciais, de transporte, que se encontrem, de alguma maneira, inter-relacionados a partir das suas percepções e impactos sobre as características ambientais da bacia escolhida para a pesquisa.

O projeto voltou-se para a investigação das imagens presentes nas narrativas (orais, literárias, fotográficas, videográficas, iconográficas) sobre a paisagem urbana para o estudo da problemática ambiental inserida em uma memória coletiva das tradições e dos arranjos da vida urbana, refletindo sobre a própria produção etnográfica enquanto memória do cotidiano de comunidades em seus territórios.

A produção de documentários etnográficos e publicações em hipermídia são uma estratégia metodológica, portanto, para além da divulgação do conhecimento científico, constituindo-se como processo constante de interpretação da realidade socioambiental a partir da conceituação e classificação das imagens e da produção de novas narrativas, abrindo um diálogo importante com técnicos e pesquisadores da área ambiental (engenheiros, ecologistas, geógrafos, urbanistas etc.).

Conforme a relação proposta por Annie Cauquelin (2002) entre os conceitos de sítio (ou site) e paisagem, enquanto representação espacial, utilizamos um blog de 
internet enquanto site que incorpora ao caráter temporal e identitário dos lugares a questão situacional, ou estrutural, que coloca os lugares em relação. Sem congelar os territórios numa memória do passado sem imaginação e numa identidade absoluta (sem dinâmica), o aspecto situacional do espaço geométrico indica a transformação, a reescritura das relações espaciais e das territorialidades.

Através da memória, entende-se a importância das relações sociais, das práticas cotidianas e interações na transformação da paisagem, para além do uso econômico do solo. Portanto, as áreas naturais na cidade estão referidas a diferentes ordens situacionais, desde a sua posição estratégica global e regional (Região Metropolitana, Região Hidrográfica) até as suas relações com os demais territórios urbanos, remetendo à relação ética necessária entre esses diversos atores sociais para a construção de uma cidadania ambiental, pensada em termos de micro, meso e macroesferas éticas que estão em jogo no trabalho de campo (OLIVEIRA; OLIVEIRA, 1996).

Apesar de ser um recurso tecnológico relativamente simples e difundido, o uso de um blog $(<\mathrm{http}$ ://habitantesdoarroio.blogspot.com $>$ ) como ferramenta inseriu-se nos procedimentos de pesquisa do Banco de Imagens e Efeitos Visuais com acervos de imagens. A formação de coleções de imagens (articulando diferentes suportes como o vídeo, a fotografia, o som, a narrativa literária) nos permite ensaiar também narrativas em hipermídia (DVDs interativos, sites de internet) em que essa complexidade da realidade socioambiental contemporânea pode ser expressa nas inter- -relações entre trajetórias sociais, relatos autobiográficos, ritmos, ações cotidianas em diferentes territórios, configurações diferenciadas no tempo e no espaço de ocupação e uso da paisagem natural ou urbana.

Através da função fantástica da imaginação criadora, presente à inteligência narrativa dos moradores entrevistados, e também às narrativas reunidas em textos de cronistas, filmes, fotografias, os links no blog remetem a uma imagem do ambiente urbano como esse ambiente cósmico e social (DURAND, 2001), relacional. Na própria forma de navegação pelas imagens (entendendo textos como imagens literárias) o blog instaura uma reflexão sobre esses jogos de escalas e de temporalidades que estão presentes às representações sobre o meio ambiente no mundo urbano contemporâneo. Acrescentando a dimensão temporal inscrita na paisagem ao fator relacional entre os diferentes territórios, o objetivo é revelar conexões entre diferentes lógicas de representação do espaço, que são articuladas em uma reflexão sobre as inter-relações entre a vida cotidiana, o meio ambiente e o contexto social. Foi composta essa intertextualidade entre as imagens presentes às ciências ditas naturais com as imagens resultantes da pesquisa etnográfica, incorporando - e não excluindo - a dimensão microcósmica que constitui as paisagens locais, situando-as em relação aos demais territórios, como o centro da cidade, a Região Metropolitana e demais localidades da Bacia Hidrográfica e, dessa forma, em relação às discussões sobre a qualidade do ambiente planetário e os debates contemporâneos sobre os usos da água. 


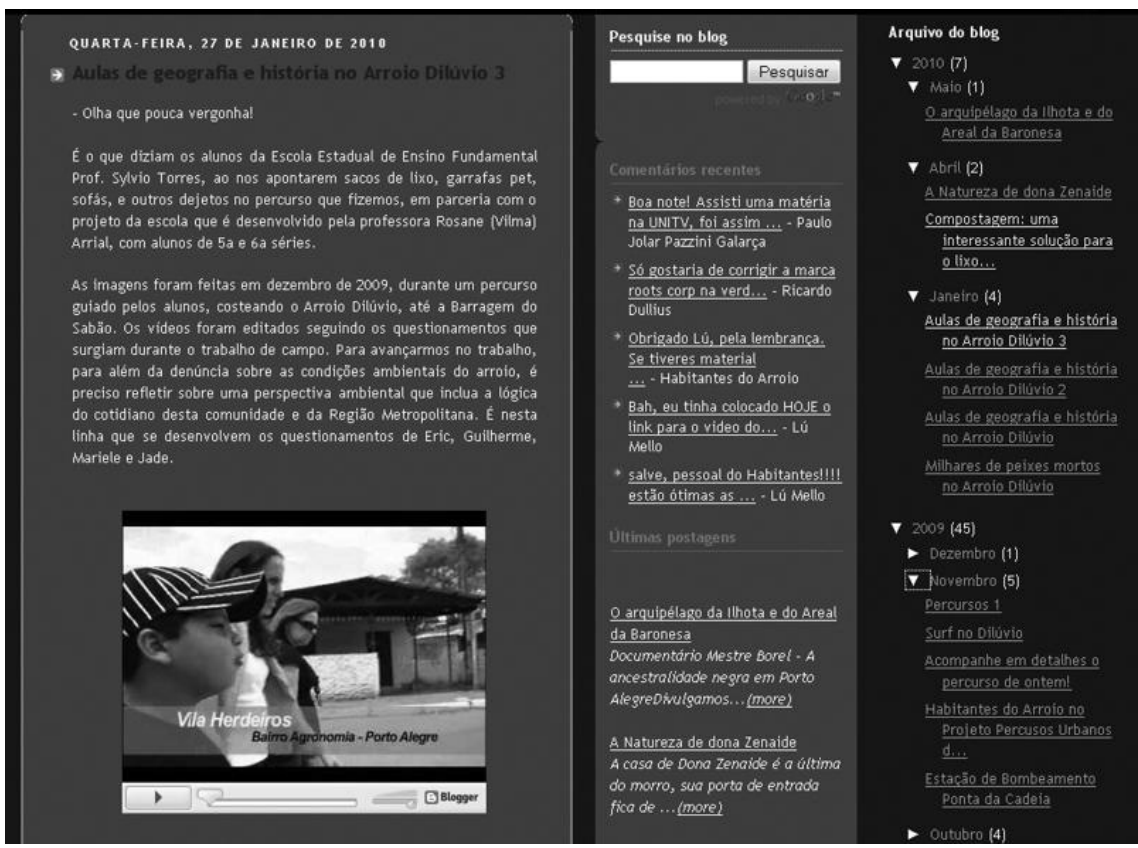

FIGURA 3 - TELA DO BLOG DO PROJETO - POSTAGEM DO PERCURSO COM CRIANÇAS E PROFESSORES EM COMUNIDADE À BEIRA DO ARROIO DILÚVIO.

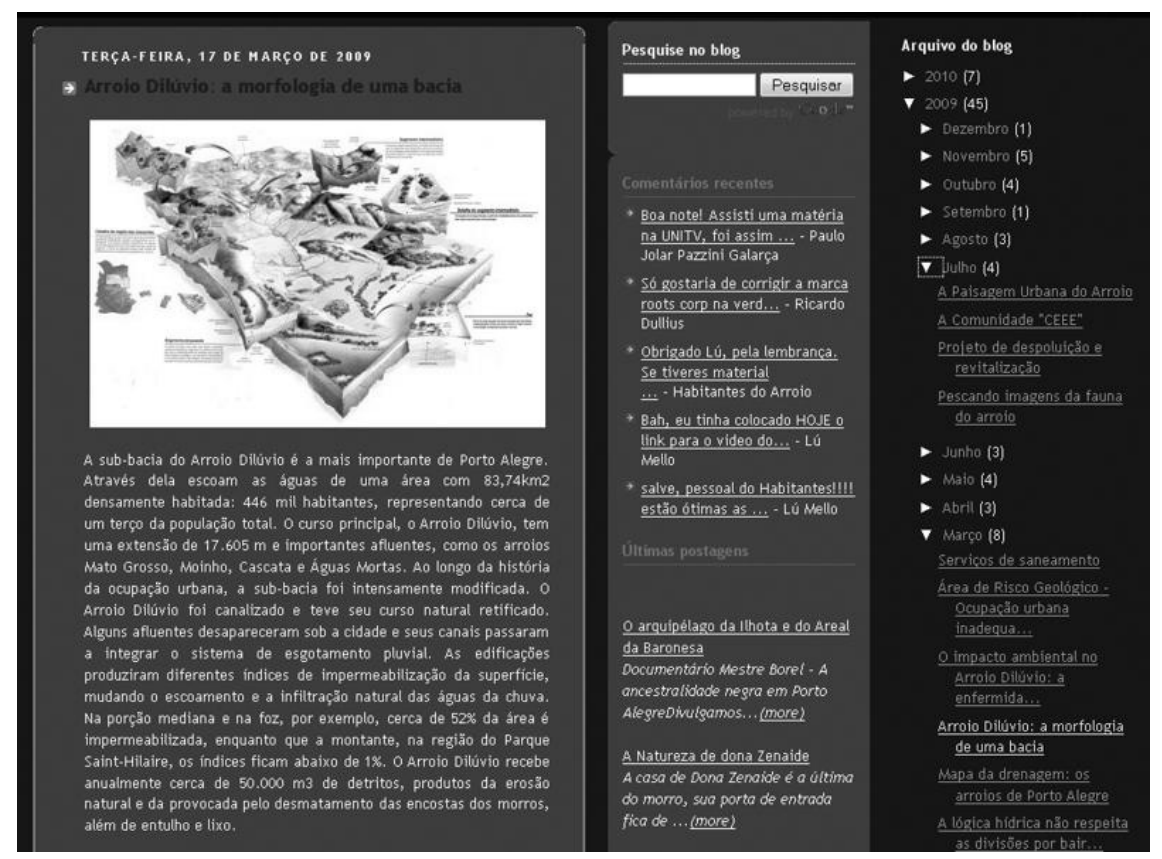

FIGURA 4 - POSTAGEM NO BLOG DO PROJETO - A MORFOLOGIA DA BACIA DO ARROIO DILÚVIO, PUBLICADA NO ATLAS AMBIENTAL DE PORTO ALEGRE. 


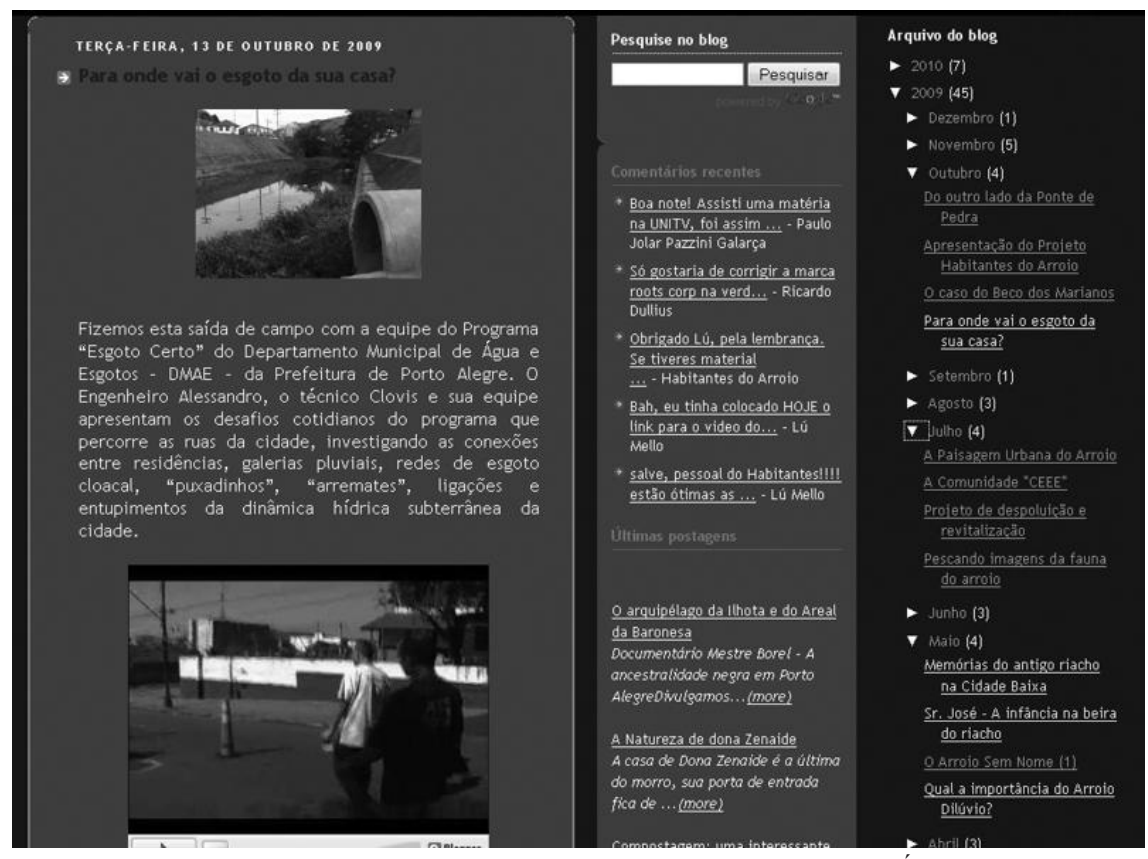

FIGURA 5 - POSTAGEM NO BLOG DO PROJETO - ENTREVISTA COM TÉCNICOS DO PROGRAMA ESGOTO CERTO - DMAE - PREFEITURA DE PORTO ALEGRE PONTO.

\section{Referências}

ARANTES, A. Paisagens paulistanas: transformações do espaço público. Campinas, SP: Ed. da UNICAMP; São Paulo: Imprensa Oficial, 2000.

BACHELARD, G. A dialética da duração. São Paulo: Editora Ática, 1988.

. A poética do espaço. São Paulo: Editora Ática, 2000. Le site et la paysage. Paris: PUF, 2002.

CERTEAU, M. de. A invenção do cotidiano. Artes de fazer. Petrópolis: Vozes, 1994.

CORBIN, A. Le miasme et La Jonquille. Paris: Flammarion, 1986.

. A Questão Ambiental sob a ótica da antropologia dos grupos urbanos, nas ilhas do Parque Estadual Delta do Jacuí, Bairro Arquipélago, Porto Alegre, RS. Tese (Doutorado em Antropologia Social) - UFRGS. Porto Alegre, 2007.
DUARTE, L. F. D. Da vida nervosa nas classes trabalhadoras urbanas. Rio de Janeiro: Jorge Zahar Editores/Brasília: CNPq, 1986.

. Risk and blame: essays in cultural theory. London; New York: Routledge, 1992.

DUMONT, L. O individualismo, uma perspectiva antropológica da ideologia moderna. Rio de Janeiro: Rocco, 1983.

As estruturas antropológicas do imaginário. São Paulo: Martins Fontes, 2001.

ECKERT, C.; ROCHA, A. O tempo e a cidade. Porto Alegre: UFRGS, 2005.

HALBWACHS, M. A memória coletiva. São Paulo: Vértice, 1990.

. Ecologia política como etnografia: um guia teórico e metodológico. Horizontes Antropológicos, v. 12, n. 25, 2006. 
LOPES, L. Sobre processos de "ambientalização" dos conflitos e sobre os dilemas da participação. Horizontes Antropológicos, v. 12, n. $25,2006$.

MAFFESOLI, M. No fundo das aparências. Petrópolis: Vozes, 1996.

MAUSS, M. Sociologia e Antropologia. São Paulo: Cosac \& Naify, 2003.

MOLLES, H.; ROHMER, E. Labyrinthes du Vecu. L'Espace: matière d'actions. Paris: Librairie des Meridiens, 1982.

MONTEIRO, C. Porto Alegre e suas escritas - Histórias e Memórias. Tese (Doutorado em História) - PUC-SP. São Paulo, 2001.

OLIVEIRA, R. C.; OLIVEIRA, L. R. C. Ensaios antropológicos sobre moral e ética. Rio de Janeiro: Tempo Brasileiro, 1996.

OLIVEN, R. G. Antropologia de grupos urbanos. Petrópolis: Vozes, 1995.
ROCHA, A. L. C. Le santuaire de désodre: l'art de savoir vivre des tendres barbares sous les Tristes Tropiques. Tese (Doutorado em Antropologia) - Paris V, Sorbonne. Paris, 1994.

SCLIAR, M. Os mistérios de Porto Alegre. Porto Alegre: Gaúcha, 1976.

SILVA, V. As esquinas sagradas do candomblé. In: MAGNANI, J. G. C.; TORRES, L. de L. (Org.). Na metrópole: textos de antropologia urbana. São Paulo: EDUSP/FAPESP, 1996.

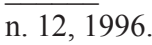

A filosofia da paisagem. Revista Política \& Trabalho, . Philosophie de la Modernité. La femme, la ville, l'individualisme. Paris: Payot \& Rivages, 2004.

VELHO, G. Individualismo e cultura: notas para uma antropologia das sociedades complexas. Rio de Janeiro: Zahar, 1981.

. Projeto e metamorfose: Antropologia das sociedades complexas. Rio de Janeiro: Zahar, 1999.

Recebido em maio de 2010.

Aceito em setembro de 2010. Publicado em dezembro de 2010. 